\title{
Longstanding dental pathology in Neandertals from El Sidrón (Asturias, Spain) with a probable familial basis
}

Dean, M.C. ${ }^{1}$, Rosas, A. ${ }^{2 \#}$, Estalrrich, A. ${ }^{2}$, García-Tabernero, A. ${ }^{2}$, Huguet, R. ${ }^{3}$, Lalueza-Fox, C. ${ }^{4}$, Bastir, M. ${ }^{2}$ and de la Rasilla, M. ${ }^{5}$

1- Department of Cell and Developmental Biology, University College London, Gower Street, London WC1E 6BT, UK. chris.dean@ucl.ac.uk

2- Paleoanthropology Group, Department of Paleobiology; Museo Nacional de Ciencias Naturales-CSIC, calle José Gutiérrez Abascal 2, 28006 Madrid, Spain._arosas@mncn.csic.es; $\quad$ aestalrrich@mncn.csic.es; agarciatabernero@mncn.csic.es; mbastir@mncn.csic.es

3- Institut Català de Paleoecologia Humana i Evolució Social (IPHES) -Unidad Asociada al CSIC, Campus Sescelades, (Edifici W3), Universitat Rovira i Virgili (URV). Carrer Marcel.lí Domingo s/n. 43007 Tarragona, Spain. rhuguet@iphes.cat

4- Institute of Evolutionary Biology (CSIC-UPF), Carrer Dr. Alguader 88, 08003 Barcelona, Spain. carles.lalueza@upf.edu

5- Área de Prehistoria Departamento de Historia; Universidad de Oviedo. Calle Teniente Alfonso Martínez s/n, 33011 Oviedo, Spain. mrasilla@uniovi.es 
\# Corresponding author: Antonio Rosas. ${ }^{1}$ Paleoanthropology Group. Department of Paleobiology, Museo Nacional de Ciencias Naturales, CSIC, Calle José Gutiérrez Abascal 2, 28006 Madrid, Spain. Tel: +34 915668973 Fax: +34 9156689 60. arosas@mncn.csic.es

\section{Abstract}

Two Neandertal specimens from El Sidrón, northern Spain, show evidence of retained left mandibular deciduous canines. These individuals share the same mitochondrial (mtDNA) haplotype indicating they are maternally related and suggesting a potential heritable basis for these dental anomalies. Radiographs and medical CT scans provide evidence of further more extensive dental pathology in one of these specimens. An anomalous deciduous canine crown morphology that developed before birth subsequently suffered a fracture of the crown exposing the pulp sometime after eruption into functional occlusion. This led to death of the tooth, periapical granuloma formation and arrested deciduous canine root growth at an estimated age of 2.5 years. At some point the underlying permanent canine tooth became horizontally displaced and came to lie low in the trabecular bone of the mandibular corpus. A dentigerous cyst then developed around the crown. Anterior growth displacement of the mandible continued around the stationary permanent canine leaving it posteriorly positioned in the mandibular corpus by the end of the growth period beneath the third permanent molar roots, which, in turn, suggests a largely horizontal growth vector. Subsequent longstanding repeated infections of the expanding cyst cavity are evidenced by bouts of bone deposition and resorption of the boundary walls of the cyst cavity. This resulted in the establishment of two permanent bony drainage sinuses, one through the buccal plate of the alveolar bone anteriorly, immediately beneath the infected deciduous canine root, and the other through the buccal plate anterior to the mesial root of the first permanent molar. It is probable that this complicated temporal sequence of dental pathologies had an initial heritable trigger that progressed in an unusually complex way in one of these individuals. During life this individual may have been largely unaware of this ongoing pathology. 
Keywords: Neandertal, dental pathology, dentigerous cyst, canine impaction.

\section{Introduction}

Previously, López-Valverde et al. (2012) and Prieto and Abenza (1999), and Prieto (2005) have described multiple dental pathologies in an adult Neandertal hemi-mandible (Adult 2; SDR-007/008) from El Sidrón, northern Spain (Fortea et al., 2003). Adult 2 represents one of 13 individuals preserved in the sample from El Sidrón (Rosas et al., 2006; 2012). The mandible is preserved from the left ascending ramus round to the mesial aspect of fractured right canine socket, but is missing the posterior border, condyle and coronoid process of the left ascending ramus. López-Valverde et al. (2012) noted several dental abnormalities including a retained left deciduous canine with an anomalous crown morphology, a radiolucent periapical area beneath the mesial root of the left first permanent molar and an unerupted left permanent canine lying low in the mandibular body beneath the second and third molar roots.

Dental pathology in fossil hominins is comparatively rare and this specimen offers an exceptional opportunity to study a number of untreated disease processes that may have accumulated and progressed in parallel over the lifetime of the individual. Judged by the completed M3 root apexes and the minimal occlusal wear on the left M3 this individual was a young adult at the time of death but some of these dental pathologies must have arisen before birth and others been acquired or developed gradually over many years.

New medical CT images of the specimen now allow us to put together a more comprehensive picture of the dental pathology present in this mandible. It is also now possible to piece together a better chronological history of how 
these pathologies may have developed over the lifetime of the individual. Moreover, there is now genetic evidence about the familial relationships between some specimens at El Sidrón. Particularly in this respect, an adolescent individual, Adolescent 3, represented only by isolated teeth and a small fragment of mandible shares the same mtDNA haplotype as the Adult 2 hemi-mandible described here (Lalueza-Fox et al., 2011). This individual also shows evidence of shared dental pathology with the Adult 2 hemi-mandible.

Individual 2 from El Sidrón preserves most of the lower dentition and a complete maxilla has been associated with this individual. It retains, even post-fossilization, severe dental calculus deposits, with the maxillary left premolars and molars either partially or totally covered. There is also an asymmetry in the degree of occlusal wear between the right maxillary dentition which is more advanced -more evident in the canine-,, and the left one. Regarding the pattern of para-masticatory dental wear, and despite Adult 2 having a large number of instrumental striations indicating a right-handed preference (Estalrrich and Rosas, 2013), some striations on the anterior teeth are nevertheless distinctive of left-handedness suggesting some degree of interchangeable hand-use in this individual. This observation may be of relevance in trying to interpret whether or not any occlusal wear asymmetry might derive from one or other of the dental pathologies described in this paper.

\section{Materials / Methods}

Lateral radiographs, periapical radiographs and medical CT scans (slice thickness $0.625 \mathrm{~mm}$, pixel size $0.344 \mathrm{~mm}$ ) were made of the Adult 2 Neandertal hemi-mandible, and of the mandibular fragment of the adolescent specimen, and reconstructed in Amira 4 (VSG). Besides these, conventional radiographs were also taken. Additional observations and measurements were made directly on the specimens. 


\section{Description of the specimens}

The dental pathology of Adult 2; mandible SDR-007-008

Both permanent central incisors are missing from the Adult 2 mandible, lost post-mortem, but both lateral incisors are present (although the left lateral incisor is now removed from the specimen). The permanent left canine is unerupted (Figure 1) and lies horizontally low in the mandibular corpus. Its incisal tip lies in line with the mesial root apex of the M2 $15 \mathrm{~mm}$ below the alveolar bone margin and $\sim 20 \mathrm{~mm}$ above the lower border of the mandible (Figure 2). The canine root apex lies $\sim 3 \mathrm{~mm}$ distal to the distal M3 root apex and protrudes through a fenestration $(7 \times 10 \mathrm{~mm})$ in the lingual cortical plate of the submandibular fossa, well beneath the mylohyoid line. The canine lies immediately lingual to the inferior alveolar nerve bundle (Figure 2) but the external contours of the mandibular bone are normal both lingually and buccally. CT scans show that the pulp chamber and pulp canal of the unerupted canine are small and reduced suggesting an older rather than a younger tooth that has continued to form secondary dentine for some while despite being unerupted and non-functional.

A retained deciduous canine is positioned between the left lateral incisor and the P3 (Figure 3). The deciduous canine crown is abnormal in its morphology but its root appears normal. The surface enamel immediately above the cervix also appears normal but this part of the crown is somewhat peg-shaped and surmounted occlusally by an additional cap of enamel. The cap expands as a dilatation from a clear constriction where it joins the true crown to form a flat worn surface that was in occlusion with the distoplalatal aspect of the upper left canine. Occlusally the crown is $\sim 3 \mathrm{~mm}$ wide mesiodistally and has contact facets for the lateral incisor mesially and the P3 distally. It appears to have been tightly integrated into the dental arch and in functional occlusion.

The overall appearance is of a peg-shaped deciduous tooth crown joined head-to-head at a mid-crown constriction with an upper portion set at 90 degrees to the long axis of the main root canal and pulp chamber of the tooth 
(Figure 3). On the buccal aspect of the abnormal enamel extension there is a circular 'crater-like' feature comprising a fractured enamel rim and dentine core with an exposed central pulp horn in its base. A part of the bulbous upper crown extension appears to have fractured off here leaving an exposed portion of its pulp horn in direct communication with the main pulp chamber and root canal. On CT scans a continuous rim of enamel surrounds a central dentine core that has fractured through on the buccal aspect at a point where the two pulp horns meet at an isthmus (Figure 3). The retained deciduous tooth root appears normal and measures $\sim 10 \mathrm{~mm}$ long. At the cervix the root is $3 \mathrm{~mm}$ mesiodistally $\times 4 \mathrm{~mm}$ buccolingually in transverse cross-section. However, the root has a wide-open apex and a wide pulp canal consistent with incomplete root formation.

The premolar crowns show no signs of any pre-mortem pathology such as caries, crown fractures or discolouration. Enamel wear facets buccally are only just through to dentine on the P4. The M1 crown shows no signs of any pre-mortem pathology and has only small islands of dentine wear exposed over the buccal cusps. The M2 shows a few enamel wear facets on the cusp tips. On the M3 there are only minimal enamel wear facets. Neither M2 nor M3 shows any evidence of pre-mortem crown pathology although there are heavy deposits of supragingival calculus on the lingual aspects of M1 and M2 with some evidence of early lingual crestal bone resorption in this position (López-Valverde et al. 2012). On the CT images there are several obvious post-mortem shrinkage fractures through the premolar and molar crowns and roots (Figure 2).

\section{The bony pathology of Adult 2}

Anteriorly, a large buccal sinus ( $10 \times 8 \mathrm{~mm})$ emerges from an extensive bony cavity beneath the roots of the left lateral incisor and deciduous canine (Figure 1). The alveolar margin of the buccal plate at the top of the sinus opening may have been intact at death since there is fresh fractured trabecular bone mesial to the deciduous canine root. At the buccal opening of 
the sinus two bony cavities appear to have coalesced into one. Beneath the incomplete deciduous canine root apex there is a rounded eroded bony cavity typical of a periapical granuloma. Rising up lingually and inferiorly from the floor of the main bony cavity is a separate funnel-shaped sinus that opens low down beneath the lateral incisor root apex to merge with the cavity beneath the deciduous canine root (Figure 1).

A large mental foramen, typical of Neandertals, opens midway between the mesial and distal M1 roots. This lies $20 \mathrm{~mm}$ below the margin of the buccal alveolar bone and10 mm below the distal M1 root apex. Two small vascular foramina open anterior to the mental foramen, one beneath the mesial M1 root and one higher up beneath the P4 root apex (Figure 1).

A large buccal sinus with well-established smooth rolled bony margins has exposed the apical two thirds of the mesiobuccal M1 root (Figure 1). Some of the crestal alveolar bone from the superior margin of the sinus margin may have been lost post-mortem giving the false impression of a deep infrabony periodontal pocket here. On lateral radiographs it appears that an apical granuloma surrounding the mesial M1 root is the true source of this buccal sinus (Figure 2). However, much of the M1 root is still surrounded by bone and there is no focal bone loss around the whole of the mesiobuccal root apex. A more likely primary source appears to be a large bony sinus tract that rises from beneath the P4 root distobuccally. Running across the mesial M1 root this has eroded much of the bone overlying it (Figure 2). Secondary involvement of the M1, however, cannot be ruled out since on some of the CT scan slices (but less clear on lateral radiographs) the distal M1 root apex and its surrounding bone seem to show periapical changes consistent with a nonvital tooth. There is, however, no obvious primary cause for this, such as caries, pre-mortem tooth fracture, tooth discolouration or pulp exposure through wear.

Lingually, beneath the root apicies of M3, the apical third of the buried canine root protrudes through an oval $7 \times 10 \mathrm{~mm}$ fenestration in the cortical bone of the submandibular fossa below the mylohyoid line (Figure 1). It's upper 
margin is $15 \mathrm{~mm}$ below the alveolar crest distal to M3. There is no sign of bone resorption or periapical infection here i.e. the root apex has maintained a knife-edge rim of bone peripherally. A small pinprick hole $1 \mathrm{~mm}$ diameter below the lingual M2 mesial root apex can be seen on CT scans to communicate with a cyst-like cavity within the mandibular body (Figure 2).

The cyst cavity within the Adult 2 mandible

Lateral X-rays show clearly the unerupted permanent canine lying low in the mandibular body. However, López-Valverde et al. (2012) have noted the heavily mineralised bone of this specimen and so as a result there is little evidence on lateral radiographs of any bony pathology within the mandibular corpus. Medical CT scans of the specimen now reveal clearly that the unerupted canine is associated with an extensive cyst cavity within the body of the mandible. This cavity completely surrounds the crown of the canine to its cervix, but not the root, which appears to have a normal but reduced periodontal ligament space. The floor of the cavity is regular in its contour and runs parallel with the lower border of the mandible $\sim 10 \mathrm{~mm}$ above it. The roof of the cavity is irregular in outline and runs below the bone beneath the M2 and $\mathrm{P} 3$ roots but extends up and between the mesial M1 and P4 roots and is in close association with these roots. The cyst cavity (Figures 2 and 4) communicates anteriorly with the sinus beneath the lateral incisor and deciduous canine roots and also extends buccally beneath P4 to emerge as a second sinus opening through the buccal cortical bone between P4 and M1. There is no obvious erosion or resorption of the roots of any teeth in the mandible. The P4 root in particular appears to be in direct contact with the cyst cavity but has a normal root apex appearance. In places, the bone lining the cavity wall shows evidence of repeated remodelling; regular contours of bone of lower densities follow the cavity boundaries and overlie those of higher densities or vice versa (Figure 4).

\section{Genetic analyses}


Recent genetic analyses support the taphonomic and archaeological hypothesis that El Sidrón represents a synchronic assemblage of a Neandertal family group. Mitochondrial (mtDNA) data suggest that the group was kinship-structured, being the same mtDNA haplotype present in 7 out of 12 individuals. The mtDNA diversity inferred from 12 individuals is significantly lower than any random subsample of sequences from unrelated modern Europeans (Lalueza-Fox et al., 2011), taken as a reference for comparison.

Adult 2 and Adolescent 3 are both males and may be related through female line as they share the same mtDNA haplotype -the one with the highest frequency out of the three detected in the assemblage-. A possible kinship between them, in accordance to their relatively similar age, would be brothers or maternal cousins. Other potential maternal relationships (e.g, unclenephew; granduncle-nephew) are less likely or can be excluded because of the age similarity. However, considering the general low mtDNA genetic diversity found in Western European Neandertals (Briggs et al. 2009), it cannot be excluded that some individuals sharing the same mtDNA haplotype in the group might be in fact more distantly related.

Of course the mtDNA relationships are not as informative for family relationships as other types of DNA genotyping; additional genomic information could clarify in the future the genealogical links between these two El Sidrón individuals. The genetic basis for deciduous canine retention, consequence of previous amelogenesis defects, possibly has an autosomal origin (Brook, 2009), although some X-chromosome genes associated to dental pathologies are known. Defects in enamel formation create the condition known as Amelogenesis Imperfecta (Al) commonly inherited as an autosomic trait. ENAM mutations appear to be responsible for a big part of the autosomaly inherited cases, but genetic studies provide evidence for the existence of at least one further autosomal Al loci (Kärrman et al. 1997). Additionally, it has been suggested that regulatory regions such as 
microRNAs repressing the ENAM gene could be involved in the inheritance of these anomalous dental traits (Lopez-Valenzuela et al. 2012).

\section{The dentition of Adolescent 3}

This individual consists of isolated upper left I1, 12 canine P3, P4 and two upper molar crowns, M2 and M3 (Figure 5). The upper M2 has very minimal cusp tip wear facets on the palatial cusps and a minimal elongated polished facet on the mesial marginal ridge but the M3 has no wear at all. The root was at an early stage of development and the tooth was likely unerupted. There is one additional right $\mathrm{M} 3$ crown, similar in morphology with the left one and also without occlusal wear, but with no root preserved.

The upper incisors are both worn through to a dentine edge. The upper left canine has a crown length of $12 \mathrm{~mm}$ but with 2 or $3 \mathrm{~mm}$ of cuspal wear loss that has exposed an island of dentine. This is continuous distally with a very strong wear facet (for the lower P3 mesial occlusal contact facet) along the distal marginal ridge. Mesially there is little more than an elongated polished enamel facet but no wear at all on the mesial marginal ridge. Notably, there is no notched wear facet between the upper left lateral incisor and upper canine for the tip and distal ridge of a lower canine.

The lower teeth preserved are the isolated right P4 and left P4, which is now separate from a small portion of the left mandibular fragment but with only the crown and a small $5 \mathrm{~mm}$ portion of its root preserved buccally. The left P3 is still implanted in the mandibular fragment that also contains the socket for the lower left P4 (Figure 5). The lower left P3 shows slight enamel wear occlusally and more marked wear on its distal slope but has no a proximal contact facet for a left lower canine mesially.

A small retained deciduous canine root lies mesial to the $\mathrm{P} 3$ but the crown is fractured off transversely post-mortem at the level of the alveolar crest (Figure 5). This retained deciduous root measures $\sim 5 \mathrm{~mm}$ buccolingually $\times 4 \mathrm{~mm}$ mesiodistally at the alveolar crest. On periapical x-rays the root is 11 to12 mm 
long. No deciduous canine root apex is visible protruding through the fractured base of the alveolar bone fragment beneath.

No lower permanent canine was present in the dental arch. By association, based on an identical pattern of linear hypoplastic banding of upper and lower canines, a lower left permanent canine crown appears likely to belong to the same individual (Figure 5). This is unworn with a crown height of $14 \mathrm{~mm}$ and only $8 \mathrm{~mm}$ of fractured root preserved buccally. The pattern of wear in both upper and lower permanent teeth suggests the lower permanent canine was unerupted (or else erupted out of the dental arch and so out of functional occlusion). It seems clear the deciduous canine was retained with a completed but unresorbed root in this individual.

\section{Discussion}

It is recognised that anomalies in size, shape and number of the deciduous dentition are often subsequently associated with anomalies in permanent tooth development (Brook and Winter, 1970; Shah et al., 2007). Brook (2009) has emphasised that the processes underlying many dental anomalies are "multifactorial, multilevel, multidimensional and progressive over time" and that a number of dental defects are known to be heritable. With this in mind it is logical to discuss the various dental pathologies in these Neandertal specimens in the chronological order that each might have arisen.

\section{Abnormal deciduous crown morphology}

The anomalous crown shape of the retained deciduous canine in the Adult 2 Neandertal would have been determined before birth as the inner enamel epithelium of the tooth germ mapped out the future shape of the enamel dentine junction. This would have been very early in gestation at around 1015 weeks and before the time initial mineralisation of the deciduous canine germ begins. This has been reported to occur in modern humans around 20 weeks gestation (Sunderland et al. 1987). 
While fused teeth result from the enamel and dentine of two separate teeth coming together, and geminated teeth from the division of a single tooth germ into a bifid crown, (Shah et al. 2007), the anomaly in this Neandertal specimen best resembles a dilated odontome where a part of the crown shows marked enlargement (Thoma and Goldman, 1946). Most often, a dilatation of the inner enamel epithelium beyond the normal outline of the tooth crown invaginates back into the growing tooth germ to form a so called dens in dente or 'tooth within a tooth' (Beynon, 1982; Alani and Bishop 2008). In this case the inner enamel epithelium appears to have expanded into a dilated extension over the cusp tip that has subsequently continued to form enamel over the whole dentine core that contains a pulp chamber with a narrow cental isthmus. Clearly, in this individual it did not prevent the normal eruption of the tooth into function. It seems most probable that biting on this tooth resulted in the fracture of a portion of the dilated crown extension buccally exposing the pulp at its isthmus and resulting in pulp necrosis and arrested root development. The stage of deciduous canine root formation suggests this would have been at around 2.5 years of age by modern human standards (Liversidge and Molleson, 2004). Exposure of the pulp to the oral environment and subsequent necrosis and chronic infection usually result in a periapical granuloma formation and in this case it seems most probably the granuloma became abcessed and then drained via a sinus into the labial gingival sulcus. If the deciduous canine root apex at this age was positioned below the level of lip muscle attachments to the mandible in this region it is possible a sinus would have tracked through soft tissues and become established as a fistula that communicated externally through the skin of the 'chin'. More common, and more likely, is establishment of a sinus draining low into the labial sulcus intra-orally.

Permanent canine tooth germs first appear as an anlarge on the lingual aspect of the deciduous tooth germ (Figure 6: Broomell 1897). These tooth germs begin to expand within their follicles that are in turn contained within a bony crypt before birth and before the end of deciduous canine crown 
completion. They continue to do so well before mineralisation of the permanent canine begins at about 6 months postnatally. It is possible an enlarged anomalous deciduous tooth germ might have displaced the closely associated permanent tooth germ early in its development, which then continued to develop in a more horizontal position than usual. However, teeth fail to erupt for many reasons and this is just one possibility. The fact that two related Neandertals both have retained deciduous canines strongly suggests a genetic component underlying the non-eruption of the left permanent canines in these specimens. This may or may not have been related to the earlier abnormal development of the deciduous crown in one of these individuals but failure to erupt was certainly a likely trigger for the subsequent cyst that formed around the left permanent canine in Adult 2.

\section{Cysts in the jaws}

Unerupted teeth may occasionally develop cysts around their crowns. While this may only happen in 1 in 100 to 150 unerupted teeth, the incidence of impacted teeth and of dentigerous cysts is near-identical. For example, the incidence of impacted mandibular canines is $3.5 \%$ and that of cysts associated with mandibular canines $3.8 \%$. The incidence of impacted mandibular M3s is $48 \%$ and that of cysts associated with mandibular M3s 46\% (Shear and Speight, 2007).

A cyst is a pathological sac-like cavity lined with an epithelium and filled with fluid or semi-fluid like material. Most benign cystic lesions of the jaws tend to increase in size over time because of growth of their lining, increased osmolarity of their contents drawing in more fluid and through bone resorption mediated by many chronic inflammatory products (Toller, 1970; Killey and Kay, 1972; Sandy et al. 1998). Faster growing cysts tend to expand in a spherical manner and have greater bone resorbing activity. Slower growing cysts tend to extend preferentially along the less dense trabecular bone with little resorption or expansion of the dense cortical mandibular or maxillary bone (Killey and Kay, 1972; Sandy et al. 1998). 
There are many classifications of benign cystic lesions of the jaws (Shear and Speight, 2007) but the cyst associated with the unerupted permanent canine of Adult 2 most closely resembles a typical dentigerous cyst where the crown of the unerupted tooth is entirely enclosed by expansion of its follicle. Importantly in this classification, the follicle remains attached at the tooth cervix. Nevertheless, another possibility is that this is an example of an odontogenic keratocyst. These cysts are in many ways similar to dentigerous cysts but can only be distinguished for certain by the nature of their epithelial lining, which is clearly never possible in fossil material. Odontogenic keratocysts, however, are probably genetically determined rather than acquired (Shear and Speight, 2007).

Interestingly with respect to the Adult 2 Neandertal, there is some evidence that many dental cysts may originate from fluid accumulation between one or other layers of the developing tooth germ, either within the stellate reticulum or between the reduced enamel epithelium and the enamel surface. Some enamel hypoplasias may have a similar aetiology. Moreover, anomalous deciduous tooth development and or inflammation from a deciduous tooth has previously been implicated in initiating some cysts associated with permanent teeth but this has never been substantiated with certainty (Robinson, 1945; Thoma and Golman, 1960; Bartlett, et al. 1973; Atkinson, 1977; Al-Talabani and Smith, 1980; Shibata et al. 2004; Lustmann and Shear, 1985).

\section{Secondary infection of cyst cavities}

While the primary lesion associated with the unerupted canine in Adult 2 is likely to be a dentigerous cyst, there is clear evidence that this became chronically infected. At death, the picture is of a longstanding and repeatedly infected dentigerous cyst showing evidence of cycles of bone deposition and resorption at its boundary walls. An obvious source of initial infection is the apical granuloma beneath the retained deciduous canine that subsequently became confluent with the cyst cavity anteriorly. Open contact of the cyst cavity with the oral environment would in itself most likely to lead to repeated bouts of acute inflammation. Other foci of secondary infection are entirely 
speculative but the sinus from the cyst emerging mesiobuccal to the M1 root was well established and may have tracked along a path of least resistance at the time the deciduous second molar was shed and the P4 was erupting beneath it. López-Valverde et al. (2012) raised the possibility that occlusal trauma led to the death of the M1 pulp that would then have drained directly into the cyst cavity. Were this indeed the case it might imply the M1 root fracture (visible in Figure 2) might have occurred premortem and not postmortem. However, given the extent of the fracture, it seems likely that at least a portion of the M1 crown would then have been lost during normal masticatory loading during life.

Often, cysts within the jaws only become apparent after many years with no symptoms at all. It is unusual for benign cystic lesions of the jaws to cause pain, paraesthesia or anaesthesia even when they are closely associated with alveolar nerves unless they become infected. Characteristically, the teeth associated with them are alive (vital) and their pulps do not die even when cysts expand around and between them. But when cysts become infected and drain into the oral cavity this leads to a continual bad taste and to increased salivary flow rates that are often associated with heavy calculus deposition. As with all infections, especially acute infections, there is then initial tenderness and swelling quickly progressing to pain and other sensory symptoms from nerve compression. In the case of large cysts, displacement of teeth then makes chewing painful. In this context the asymmetric pattern of occlusal wear is notable in this individual and perhaps attributable to preferential chewing on the least painful side of the mouth during bouts of acute infection of the cyst cavity. The pattern of alternating left-right handedness noted earlier in this individual may thus sway the explanation of occlusal wear asymmetry away from one due to a strong natural unilateral chewing pattern and towards a more likely one resulting from periods of painavoidance. A common eventual mode of clinical presentation of large cysts of the jaws and teeth is unexpected pathological jaw fracture later in life that results from greatly thinned bone from within the jaw. 
Mandible growth and displacement of unerupted teeth

The horizontal position of the unerupted canine beneath the M2 and M3 roots would have resulted partly from pressure applied to the crown by the expanding cyst that displaced the tooth distally, but also from growth of the mandible. Growth in length of the mandible occurs primarily at the mandibular condyles, which displaces the mandible anteriorly away from the cranial base (Figure 7). It is resorption of bone at the chin (and anterior border of the ascending ramus) that then remodels the mandible as it continues to grow in length and width. It seems likely that once the canine was horizontally orientated and became increasingly encapsulated by the growing cyst it remained low in this developmental position as the bone of the lengthening mandible grew forwards over and around it. Growth in length of the Neandertal mandible was potentially greater than in modern humans today. This in itself may have contributed to the position of the unerupted canine so far distally in the mandible of Adult 2.

Coquerelle et al. (2010) have described growth at the mandibular symphysis and of the developing tooth germs contained within the symphyseal alveolar bone in modern chimpanzees and modern humans. While there are clear differences in symphyseal inclination both pre- and post-natally between chimps and humans, the deciduous canines of both maintain a vertical path of eruption and do not appear to be influenced by the anterior, posterior or vertical inclination of the symphysis during mandibular growth (Figs. $5 \& 7$ in Coquerelle et al., 2010). No such studies exist, however, of the subsequent postnatal development and inclination of the permanent mandibular canine in modern humans and Neandertals. It remains possible that the posterior inclination of the symphyseal region in Neandertals goes hand-in-hand with a more posteriorly inclined permanent canine germ than in modern humans (compare the juvenile from El Sidrón with a modern child in this respect) which might predispose Neandertal permanent canine germs to further horizontal displacement within the jaws more easily than those of modern humans. While this is entirely speculative it is worthy of consideration since 
Weinberger (1948) previously illustrated another case of an unerupted left permanent canine and retained deciduous canine in Le Moustier 1 (see also Ponce De Leon and Zollikofer, 1999). Moreover, Bailey and Hublin (2006) have speculated that the Neandertal remains from Grotte du Renne (Arcy-surCure) include a completely unworn but fully formed canine with substantial cementum deposition at the root apex that may have been impacted or displaced.

\section{Conclusions}

Many dental anomalies have a heritable component to them. Here we describe two Neandertal specimens from the same family that both show evidence of retained deciduous canines and unerupted permanent canines. In one, the anomalous deciduous canine crown morphology that developed in utero (at around 10-15 weeks) predisposed it to early crown fracture and exposure of the pulp with periapical infection at $\sim 2.5$ years of age. A dentigerous cyst that developed around the unerupted permanent canine, together with anterior growth of the mandible, left it horizontally aligned and distally displaced low in the body of the mandible beneath the M2 and M3 roots. Subsequent bouts of secondary infection from a number of potential sources led to the establishment of two permanent bony sinuses draining the cyst cavity anteriorly beneath the deciduous canine root and buccally between P4 and M1. These examples of dental palaeopatholgy illustrate how a single genetic predisposition to an anomally in deciduous tooth formation can progress through a series of subsequently acquired pathological conditions. In this case they present as a complicated clinical picture post-mortem in a young adult. It is likely this individual may have been largely unaware of any of this dental pathology during life.

\section{Acknowledgements}

We thank Professors Alan Brook, Paul Speight, Bill Barrett for helpful discussions. The authors want to thank B. Fernández Cascón and the El 
Sidrón Cave excavation team. El Sidrón site is being excavated with the support of the Consejería de Cultura of the Asturias Autonomous government. This research is founded by the Spanish Ministry of Economy and Competitiveness (Project CGL2012-36682).

\section{References}

Alani, A., Bishop, K., 2008. Dens invaginatus. Part 1: Classification, prevalence and aetiology. Int. Endod. J. 41, 1123-1136.

Al-Talabani, N.G., Smith, C.J., 1980. Experimental dentigerous cysts and enamel hypoplasia: their possible significance in explaining the pathogenesis of human dentigerous cysts. J. Oral Pathol. 9, 82-91.

Atkinson, M.E., 1977. An autoradiographic study of experimental odontogenic cyst formation in the mouse. J. Oral Pathol. 6, 382-386.

Bailey, S.E. and Hublin, J-J., 2006. Dental remains from the Grotte du Renne at Arcy-sur-Cure (Yonne). J. Hum. Evol. 50, 485-508.

Bartlett, P.F., Radden, B.G., Reade, P .C., 1973. The experimental production of odontogenic keratocysts. J. Oral Pathol. 2, 58-67.

Beynon, A.D., 1982. Developing dens invaginatus (dens in dente). A quantitative microradiographic study and a reconsideration of the histogenesis of this condition. Br. Dent. J. 153, 255-60.

Brook, A.H., 2009. Multilevel complex interactions between genetic, epigenetic and environmental factors in the etiology of anomalies of dental development. Arch. Oral Biol. 54S, S3-S17.

Brook, A.H., Winter G.B., 1970. Double teeth. A retrospective study of 'geminated' and 'fused' teeth in children. Br. Dent. J. 129, 123-130. 
Broomell, I.N., 1897. Macroscopic tooth-development. Dental Cosmos. 39, 881-905.

Briggs, A.W., Good, J.M., Green, R.E., Krause, J., Maricic, T., Stenzel, U., Lalueza-Fox, C., Rudan, P., Braijkovic, D., Kucan, Z., Gusic, I., Schmitz, R., Doronichev, V.B., Golovanova, L.V., de la Rasilla, M., Fortea, J., Rosas, A., Pääbo, S., 2009. Targeted retrieval and analysis of multiple Neandertal mtDNA genomes. Science. 325, 318-321.

Coquerelle, M., Bookstein, F.L., Braga, J., Halazonetis, D.J., Weber, G.W., 2010. Fetal and infant growth patterns of the mandibular symphysis in modern humans and chimpanzees (Pan troglodytes). J. Anat. 217, 507-520.

Estalrrich, A., Rosas, A., 2013. Handedness in Neandertals from the El Sidrón (Asturias, Spain): Evidence from Instrumental Striations with Ontogenetic Inferences. PLoS One.

Fortea, J., de la Rasilla, M., Martínez, E., Sánchez-Moral, S., Cañaveras, J.C., Cuezva, S., Rosas, A., Soler, V., Julià, R., de Torres, T., Ortiz, J.E., Castro, J., Badal, E., Altuna, J., Alonso, J., 2003. La Cueva de El Sidrón (Borines, Piloña, Asturias): Primeros resultados. Estudios Geológicos. 59, 146-159.

Kärrman, C., Bäckman, B., Dixon, M., Holmgren, G., Forsman, K., 1997. Mapping of the locus for autosomal dominant amelogenesis imperfecta (AlH2) to a 4-Mb YAC contig on chromosome 4q11-q21. Genomics. 39, 164-170.

Killey, H.C., Kay, L.W., 1972. Benign cystic lesions of the jaws, their diagnosis and treatment. Churchill Livingstone, London. 
Lalueza-Fox, C., Rosas, A., Estalrrich, A., Gigli, E., Campos, P. F., GarcíaTabernero, A., García-Vargas, S., Sánchez-Quinto, F., Ramírez, O., Civit, S., Bastir, M., Huguet, R., Santamaría, D., Gilbert, P., Thomas, M., Willerslev, E., de la Rasilla, M., 2011. Genetic evidence for patrilocal mating behavior among Neandertal groups. Proc. Nat. Acad. Sci. 108, 250-253.

López-Valenzuela, M., Ramírez, O., Rosas, A., García-Vargas, S., de la Rasilla, M., Lalueza-Fox, C., Espinosa-Parrilla, Y., 2012. An ancestral allele of miR-1304 present in Neandertals regulates genes involved in enamel formation and could explain dental differences with modern humans. Mol. Biol. Evol. 29, 1797-1806.

López-Valverde, A., López-Crista, M., Prados-Frutos, J.C., Gómez de Diego, R., de Vincente, J., Cutando, A., 2012. Oral pathology in Iberian Neandertals. Afr. J. Biotechnol. 11, 6359-6363.

Liversidge, H.M., Molleson, T., 2004. Variation in crown and root formation and eruption of human deciduous teeth. Am. J. Phys. Anthropol. 123, 172180.

Lustmann, J., Shear M., 1985. Radicular cysts arising from deciduous teeth; a review of the literature and report of 23 cases. Int. J. Oral Surg. 14, 153-161.

Ponce de Leon, M.S. and Zollikofer, C.P.E., 1999. New evidence from Le Moustier 1: Computer-assisted reconstruction and morphometry of the skull. Anat. Rec. 254, 474-489. 
Prieto, J.L., Abenza, J.M., 1999a. Anomalías de la dentición en la mandíbula neandertal SDR-7-8 del Sidrón. (Poster). V Congreso Nacional de Paleopatología. Alcalá la Real (Jaén, Spain).

Prieto, J.L., Abenza, J.M., 1999b. Evidencia de patología periodontal en la mandíbula neandertal SDR-7-8 del Sidrón. (Poster). V Congreso Nacional de Paleopatología. Alcalá la Real (Jaén, Spain).

Prieto, J.L., 2005. Hallazgos paleopatológicos en la mandíbula SDR-7-8 del Sidrón. In: Montes-Barquín, R., and Lasheras-Corruchaga, J.A. (Eds.), Neandertales cantábricos, estado de la cuestión. Monografías del Museo de Altamira 20, Santillana del Mar, pp. 397-403.

Robinson, H.B.G., 1945. Classification of cysts of the jaws. Am. J. Orthod. Oral Surg. 31, 370- 375.

Rosas, A. Martínez-Maza, C., Bastir, M., García-Tabernero, A., Lalueza-Fox, C., Huguet, R., Ortiz, J.E., Julia, R., Soler, V., de Torres, T., Martínez, E., Cañaveras, J.C., Sánchez-Moral, S., Cuezva, S., Lario, J., Santamaria, D., de la Rasilla, M., Fortea, J., 2006. Paleobiology and comparative morphology of a late Neandertal sample from El Sidrón, Asturias, Spain. Proc. Nat. Acad. Sci. 103, 19266-19271.

Rosas, A., Estalrrich, A., García-Tabernero, A., Bastir, M., García-Vargas, S., Sánchez-Meseguer, A., Huguet, R., Lalueza-Fox, C., Peña-Melián, A., Kranioti, E.F., Santamaría, D., de la Rasilla, M., Fortea, J., 2012. Les 
Néandertaliens d'El Sidrón (Asturies, Espagne). Actualisation d'un nouvel échantillon. L'Anthropologie. 116, 57-76.

Sandy, J.R., Meghji, S., Harris, M., 1998. Bone remodeling in the jaws clinical considerations. In: Harris, M., Edgar, M., S. Meghji, S. (Eds.), Clinical Oral Science. Wright Publishing, Oxford, pp. 98-119.

Shah, M., Shah, P., Parikh, K., 2007. Bilateral double teeth in primary dentition with partial anodontia of permanent dentition a case report. J. Dent. Sci. 2, 51-52.

Shear, M., Speight, P.M., 2007. Cysts of the oral and maxillofacial regions. Blackwell, Munksgaard.

Shibata, Y., Asaumi, J., Yanagi, Y., Kawai, N., Hisatomi, M., Matsuzaki, H., Konouchi, H., Nagatsuka, H., Kishi, K., 2004. Radiographic examination of dentigerous cysts in transitional dentition. Dentomaxillofac. Radiol. 33, 17-20.

Sunderland, E.P., Smith, C.J., Sunderland R., 1987. A histological study of the chronology of mineralisation in the human deciduous dentition. Arch. Oral. Biol. 32, 167-174.

Thoma, K. H., Goldman, H.M., 1946. Odontogenic tumors; classification based on observations of epithelial, mesenchymal, and mixed varieties. Am. J. Pathol. 22, 433-471.

Thoma, K.H., Goldman, H.M., 1960. Oral Pathology. Mosby Editors, St. Louis.

Toller, P.A., 1970. The osmolarity of fluids from cysts of the jaws. Br. Dent. J. 128, 317-322. 
Weinberger B.W., 1948. An introduction to the history of dentistry with medical and dental chronology \& bibliographic data. Mosby Editors, St. Louis.

\section{Figure legends}

\section{Figure 1}

El Sidrón Individual 2 hemi-mandible. Lingually, (top central image) the root apex of the impacted permanent left canine is visible protruding through cortical bone beneath the M3 distal root within the submandibular fossa. Heavy calculus deposits are also visible around the premolar and molar cervix. Buccally, (bottom central image) the large mental foramen is visible beneath M1 with two accessory foramina mesial to it. Above the mental foramen a large smooth-walled sinus has exposed the mesial root of the M1. The two higher power views to the right show the sinus tract rising up from beneath the P4 root (top right image) but also that some intact bone remains around the apex of the M1 mesial root (bottom right image). Anteriorly (left image) a second buccal sinus opens deep beneath the socket of the 12 (now removed post-mortem) and this has coalesced with the apical granuloma surrounding the incomplete apex of the deciduous canine.

\section{Figure 2}

Consecutive CT slices through the left mandibular corpus of El Sidrón Individual 2. The top series are axial slices respectively through the P4, P4/M1 interproximal alveolus, mesial M1 root and distal M1 root. Beneath are consecutive slices through the crown, cervix and root respectively of the impacted permanent canine. The inferior alveolar canal lies lateral to the canine and is not involved in the cyst cavity. The crown of the canine lies within the cyst cavity but the cervix and root are surrounded by bone and/or a narrowed periodontal ligament space.

\section{Figure 3}


The deciduous canine crown of El Sidrón Individual 2 is abnormal in its morphology. An essentially peg-shaped crown has a flattened worn cap and a buccal extension that has fractured off exposing a pulp horn centrally. This communicates at right angles with the central pulp camber and root canal of the tooth. The CT image below reveals that the root arrested during development short of its full length with an incomplete and open apex. Surrounding the root apex is a bony cavity resembling that of a typical, but large and longstanding, apical granuloma. Still lower in the image, the anterior projection of the cyst cavity is visible as a central radiolucency within the trabecular bone of the mandibular corpus.

\section{Figure 4}

Four consecutive horizontal CT slices through the left corpus of El Sidrón Individual 2 with the lowest on the left and highest on the right. The lowest slice (left) cuts though the permanent canine axially along its length and shows the crown within the cyst cavity but the root surrounded by bone. The inferior dental canal lies just lateral to the canine. The tract of the sinus beneath the P4 is visible centrally and the sinus tract beneath the retained deciduous root anteriorly. The second image from the left shows the full anterioposterior extent of the cyst cavity, the third image from the left shows the opening of the sinus tract beneath the M1 mesial root (still, however, mostly surrounded by bone at its apex) and the image on the right the incomplete deciduous root positioned centrally within the radiolucent space of its apical granuloma now confluent with the cyst cavity.

\section{Figure 5}

Dentition of Adolescent 3 from the El Sidrón site. A.- Occlusal view of the complete preserved dentition. B.- Dental wear of the upper left 12 and canine. C.- Buccal view of the upper and lower canines. Note the identical pattern of linear hypoplastic banding of upper and lower canines D.- Occlusal fitting of the upper canine and lower first premolar, relating lower and upper isolated 
dental pieces. E.- Fragment of mandible in which the root of the deciduous canine can be appreciated. On the left side, a permanent canine without any sign of occlusal wear can be seen, denoting a non erupted condition.

\section{Figure 6}

At birth the follicles that contain the developing tooth germs, of all the deciduous teeth as well as those of the permanent anterior teeth and first permanent molar are present in the jaws. In the upper picture, the lingual aspect of a neonatal hemi-mandible has been dissected to show the follicles of the deciduous teeth and that of M1. In the lower picture, the follicles have been dissected out and rolled over towards the buccal. This reveals the small developing follicles of the permanent central and lateral incisors and the permanent canine. These permanent follicles are positioned lingual to their deciduous counterparts in the jaw but at this age are still attached and closely associated with them. The follicle of the first permanent molar is also present at birth and lies distal to the follicle of the dm2. At this age the dm2 is larger than the M1. (Adapted from Broomell, 1897).

\section{Figure 7}

Comparative growth series of mandible and canine development in $\mathrm{H}$. sapiens and the neandertal, individual 2 from the El Sidrón. Primary displacement and growth at the mandibular condyle results in lengthening of the mandibular corpus. The follicle containing the permanent canine tooth germ appears before birth just lingual to the developing deciduous canine. With vertical growth of the alveolus the permanent canine usually comes to lie low in the corpus but remains vertically aligned. As the deciduous canine root is resorbed the permanent canine then erupts into occlusion. In individual 2 from El Sidrón the permanent canine follicle became displaced in the alveolus very early in development tilting the axis of the tooth germ and its follicle anteriorly. Subsequent development of a cyst cavity surrounding the crown of the tooth, together with anterior growth of the mandibular body happening around it, left the permanent canine displaced posteriorly in the adult mandible low in the corpus beneath the $\mathrm{M} 2$ and $\mathrm{M} 3$ roots. 